\title{
Multifragmentary Tibial Pilon Fractures: Midterm Results After Osteosynthesis with External Fixation and Multiple Lag Screws
}

\author{
Johannes Kiene*, Jan Herzog, Christian Jürgens and Andreas Paech
}

Department of Trauma and Orthopedics, UKSH-Lübeck, Germany

\begin{abstract}
Osteosynthesis of intraarticular tibial pilon fractures is preferably achieved using locking plates via a minimally invasive technique. If combined with severe soft tissue damage there is a high risk of wound-healing deficits after plate osteosynthesis. Thus our aim was to find an alternative method of treatment for those cases with combined soft tissue injuries.

We report on five cases with comminuted fractures of the joint surface combined with critical soft tissue condition that were treated with lag screws and external fixation (AO) applied across the ankle joint. All five patients were followed up, undergoing clinical and radiological examination.

Using this approach we achieved fracture healing of comminuted fractures without further complications. Clinical followup after an average of 55.6 (36-75) months revealed a mean AOFAS score of 81 (62-100).

We therefore propose combined treatment using lag screws with external fixation as a practical treatment option for those fractures for which lag screws combined with a locking plate are not feasible or when there is a high risk of woundhealing deficits due to severe soft tissue damage.
\end{abstract}

Keywords: Pilon fracture, critical soft tissue, external fixation, lag screw.

\section{INTRODUCTION}

The fixation of bone using a flexible technique such as external fixation in combination with fixation using lag screws with absolute stability is known to be biomechanically conflicting [1] and is generally avoided in surgical fracture treatment.

Given the limited patient comfort and functional performance, temporary immobilisation of the ankle joint and relatively high rate of infection at the point of pin insertion, external fixation would appear to be disadvantageous compared to plate osteosynthesis. However, minimal contact between the implant and bone using external fixation facilitates soft tissue protection as treatment is less invasive.

Here, we report on five clinical cases with multifragment tibial pilon fractures in which implantation of a locking plate for fracture stabilisation was not possible after osteosynthesis with lag screws due to juxtaposed high-grade soft tissue damage. Fractures were thus treated with external fixation to ensure the stability of the compressionosteosynthesis. Follow-up involved clinical and x-ray examination. The results are discussed in the context of previous reports.

\section{MATERIALS AND METHODOLOGY}

Between 2005 and 2008, we treated fractures with 3.5 $\mathrm{mm}$ lag screws and modular, external fixation applied across

*Address correspondence to this author at the Department of Trauma and Orthopedics, UKSH-Lübeck, Germany; Tel: +49-4515006355;

Fax: +49-4515003647; E-mail: Johannes.Kiene@uksh.de the ankle joint in five patients (four male and one female between 19 and 67 years of age (average 46)) who had sustained a high-velocity trauma with closed, intra-articular comminuted fractures of the distal tibia [2]. One patient showed manifest compartment syndrome of the lower leg at admission after prolonged transport to the hospital, another developed compartment syndrome of the lower leg within the first 24 hours after trauma, and three had grade 2 soft tissue injuries (Classification of Oestern and Tscherne) [3] (Table 1). CT was performed in all cases for fragment analysis to guide screw insertion.

Primary fracture stabilisation was performed with external fixation, followed by second-stage treatment with additional open reduction and internal fixation with lag screws. The reduction was temporarily held by k-wires. External fixation was removed after an average of 62 days (50-86 days), followed by mobilisation of the ankle by physiotherapy and increased weight-bearing in a lower limb orthesis (Vacoped-shoe or tailor-made walking aid).

Full weight-bearing without the orthesis was achieved after an average of 22 months (122-186 days). No infectious complications at the points of pin insertion were detected. In two cases, the metalwork was completely removed after 16 and 17 months.

In all five patients we achieved satisfactory primary fracture healing without secondary fragment dislocation. Follow-up was conducted after 55.6 months on average with clinical and radiological examination. The range of movement within the joint and muscle circumference were assessed using a standardized evaluation form [4] [form F4224]. 
Table 1. Initial Findings in Patients After Sustaining Trauma

\begin{tabular}{|c|c|c|c|c|c|}
\hline Pat. & $\begin{array}{c}\text { Patient's } \\
\text { Age }\end{array}$ & $\begin{array}{c}\text { Trauma } \\
\text { Incident }\end{array}$ & $\begin{array}{c}\text { Tibial-Pilon } \\
\text { Fracture AO Class }\end{array}$ & $\begin{array}{c}\text { Soft Tissue Involvement } \\
\text { After Östern/Tscherne }\end{array}$ & $\begin{array}{c}\text { Trauma-Related } \\
\text { Complication }\end{array}$ \\
\hline \hline 1 & $40 \mathrm{y}$ & Motor-bike accident & C 3 & 2 & Compartment syndrome \\
\hline 2 & $49 \mathrm{y}$ & Fall $2 \mathrm{~m}$ & C 3 & Compartment syndrome \\
\hline 3 & $55 \mathrm{y}$ & Car accident & B 3 & 2 & none \\
\hline 4 & $19 \mathrm{y}$. & Fall $8 \mathrm{~m}$ & B 3 & C 3 & 2 \\
\hline 5 & $68 \mathrm{y}$ & Fall $4 \mathrm{~m}$ & & Tension blisters on skin \\
\hline
\end{tabular}

Patients' subjective grading was documented according to the AOFAS score [5] (excellent 90-100; good 75-89; satisfactory $60-74$; poor $<60$ points).

$\mathrm{X}$-ray examinations of the ankle joint were undertaken in the a.p. projection (with $\sim 15$ degree internal rotation) and lateral plane in the case of specific complaints, using grading for arthrosis after Kellgren and Lawrence [6].

\section{RESULTS}

In this cohort study we reviewed five patients who had sustained a high-velocity trauma with closed, intra-articular comminuted fractures of the distal tibia. Due to fracture characteristics and critical soft tissue condition, fracture stabilisation was performed using external fixation, followed by second-stage treatment with additional open reduction and internal fixation with lag screws. Follow-up (FU) took place after an average of 55.6 months (36-75 months). The mean range of movement (ROM) in the ankle joint (see Table 2) was $71 \%$ (34-100\%), compared to the ROM of the unaffected ankle. Good subjective and objective results were demonstrated by a mean AOFAS score of 81.4 points (62100) (Table 2).

\section{Patient 1}

Forty-year-old man, no co-morbidities, RTA as motorbike driver with left dorso-lateral tibial head impression facture, left middle foot fracture and closed, displaced comminuted fracture of the distal lower right leg with C3fracture of the tibial pilon and luxation fracture of the ankle including a fracture of the distal fibula. Initial treatment involved applying external fixation and plate osteosynthesis of the fibula fracture. Within 12 hours, the patient developed compartment syndrome. After decompression of the compartments of the lower leg and temporary wound coverage with artificial skin coverage, the tibia was reconstructed using small fragment screws and secondary wound closure. At 61 months FU mobilisation in the right ankle joint was actively possible with a range of pain-free movement of $10-0-30$ degrees (left $20-0-35$ degrees). AOFAS score: 82 points (Fig. 1).

\section{Patient 2}

20.06.2005: 49-year-old man, lorry driver, BMI 37.8, CVI II degree with atrophy of the skin and brown skin pigmentation, smoker with 25 pack years, arterial hypertension. Closed, isolated C3-tibial pilon fracture on right. Continued driving his lorry for about 5 hours after sustaining the injury, on admission already presenting with compartment syndrome of the lower leg. Primary treatment included compartment decompression and stabilisation using external fixation followed by osteosynthesis with nine small fragment screws after 7 days and secondary wound closure. FU 09/2011 with active movement of 5-0 - 25 degrees in the ankle joint (left $15-0-30)$. AOFAS score: 76 points. Patient has been able to continue working as a lorry driver (Fig. 2).

\section{Patient 3}

21.08.2007: 55-year-old woman, no co-morbidities. RTA, collision in a car. Closed pilon tibial fracture, B-3 with high left fibula fracture without syndesmotic injury, additional left ulna shaft fracture. Primary treatment using external fixation, secondary osteosynthesis 8 days after initial surgery with five small-fragment interfragmentary screws. FU 06/2011 with active movement of the left ankle joint of $15-0$ - 45 degrees (right $15-0-45$ degrees). AOFAS score: 100 points (Fig. 3).

\section{Patient 4}

06.10.2007: 19-year-old man, no co-morbidities, sustaining a fall from $8 \mathrm{~m}$ height through a roof. Closed right tibial pilon fracture type B-3, accompanying fracture of $2^{\text {nd }}$ and $3^{\text {rd }}$ lumbar

Table 2. Results After Follow-Up Examination

\begin{tabular}{|c|c|c|c|c|c|c|}
\hline Pat. & $\begin{array}{c}\text { Range of Movement } \\
\text { (ROM) Ankle Joint }\end{array}$ & $\begin{array}{c}\text { Differences in ROM Compared } \\
\text { to Unaffected Ankle }\end{array}$ & $\begin{array}{c}\text { Muscle Atrophy } \\
\text { of the Calf (cm) }\end{array}$ & $\begin{array}{c}\text { AOFAS } \\
\text { Score }\end{array}$ & $\begin{array}{c}\text { Arthrosis Grade on } \\
\text { X-Ray - Ankle }\end{array}$ & $\begin{array}{c}\text { Follow-Up } \\
\text { in Months }\end{array}$ \\
\hline \hline 1 & $10^{\circ}-0-30^{\circ}$ & $-15 \%-27 \%$ & 2 & 82 & 2 \\
\hline 2 & $5^{\circ}-0-25^{\circ}$ & $-20 \%-40 \%$ & 0 & 76 & 3 \\
\hline 3 & $15^{\circ}-0-45^{\circ}$ & $0 \% \%$ & 1 & 100 & 74 \\
\hline 4 & $0^{\circ}-0-40^{\circ}$ & $-5 \%-11 \%$ & 0 & 87 & 46 \\
\hline 5 & $0^{\circ}-0-10^{\circ}$ & $-20^{\circ}-66 \%$ & 2,5 & 62 & 47 \\
\hline
\end{tabular}



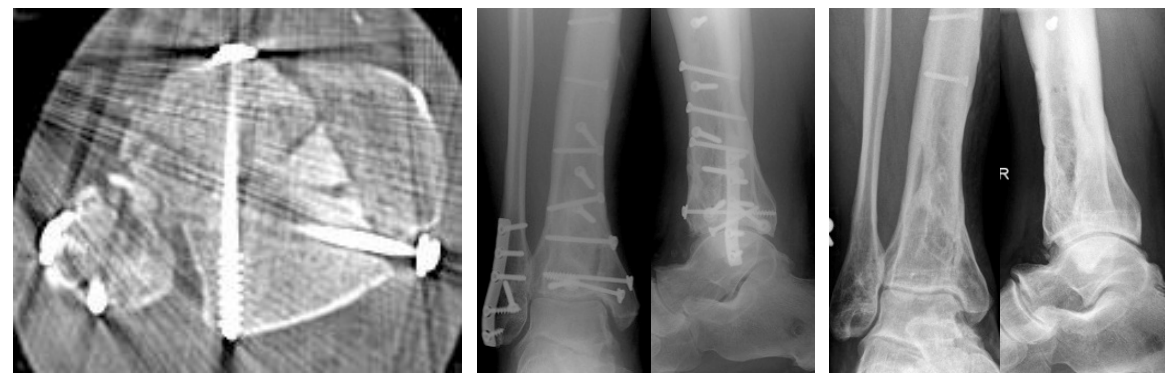

Fig. (1). Patient 1: Postoperative findings and results after 75 months (no initial radiographs available).
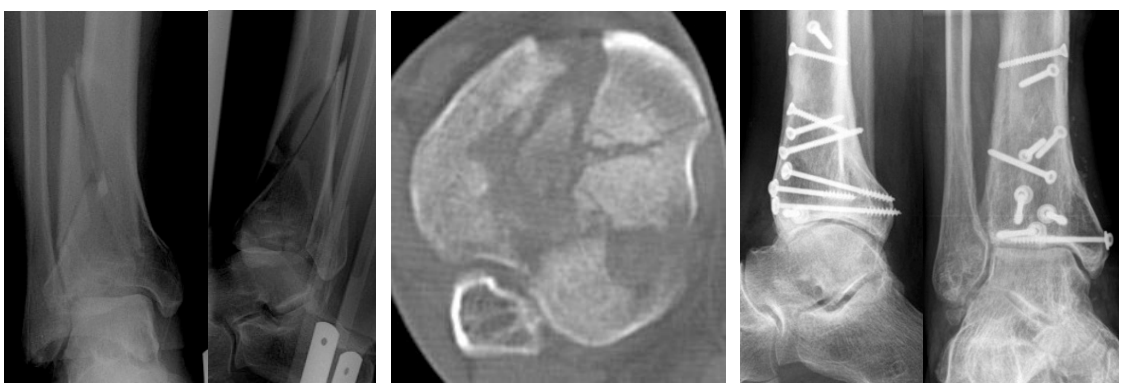

Fig. (2). Patient 2: Primary findings and results after 74 months.
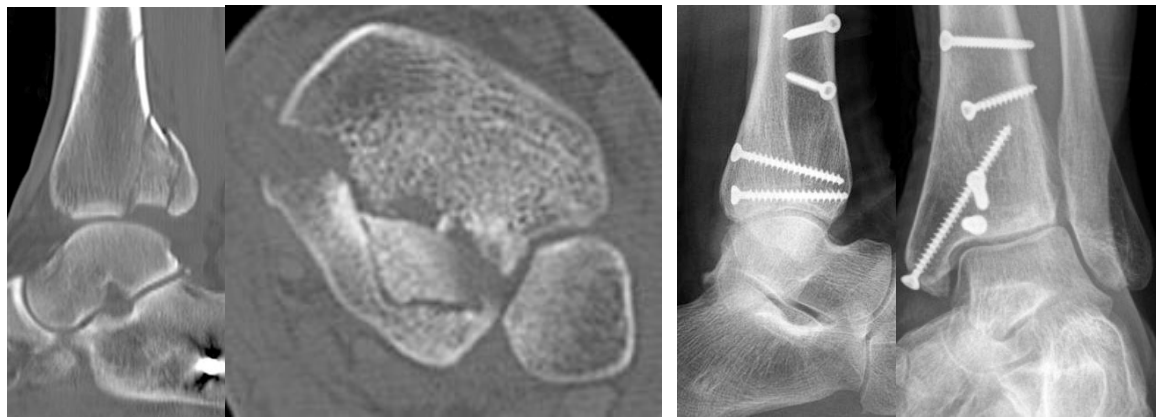

Fig. (3). Patient 3: Primary CT and results after 46 months.

vertebrae with dorsal instrumented fusion. Primary stabilisation using external fixation, osteosynthesis after 9 days using eight small fragment screws and several Ethi-Pins within the joint surface. No complications, removal of external fixation 60 days after surgery, mobilisation using orthotics for the lower leg with partial weight-bearing and increased weight-bearing status over 12 weeks. FU 08/2011 with active movement of the right ankle joint of $0-0-40$ degrees (left $10-0-35$ degrees). AOFAS-score: 87 points (Fig. 4).

\section{Patient 5}

27.02.2008: 66-year-old male, no co-morbidities, fall from $4 \mathrm{~m}$ height from scaffolding onto concrete ground, sustaining a closed pilon tibial C3-fracture including right proximal fibula fracture without syndesmotic injury and Grade II soft tissue contusion with early tension blistering of the overlying skin. Accompanying central mid-face fracture. Primary treatment using external fixation followed by treatment of the mid-face fracture 14 days after initial surgery. Osteosynthesis of distal tibia with screws and removal of external fixation on April 30th 2008 followed by mobilisation with partial weight-bearing walking aid. FU $02 / 2011$ with active movement of the ankle joint of $0-0-10$ degrees (left 10-0-20). AOFAS score: 62 points (Fig. 5).
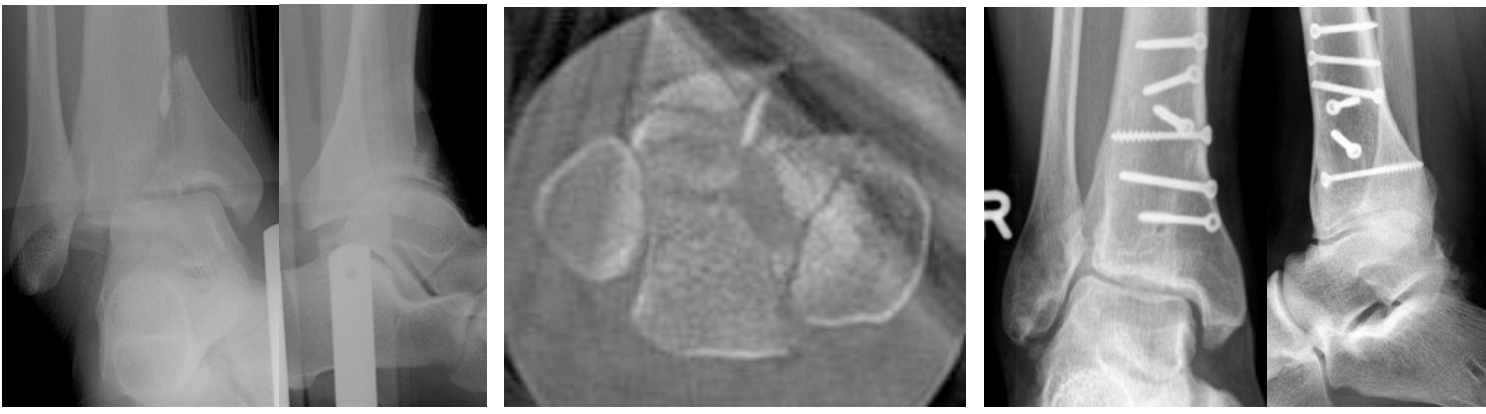

Fig.(4). Patient 4: Primary findings and results after 47 months. 


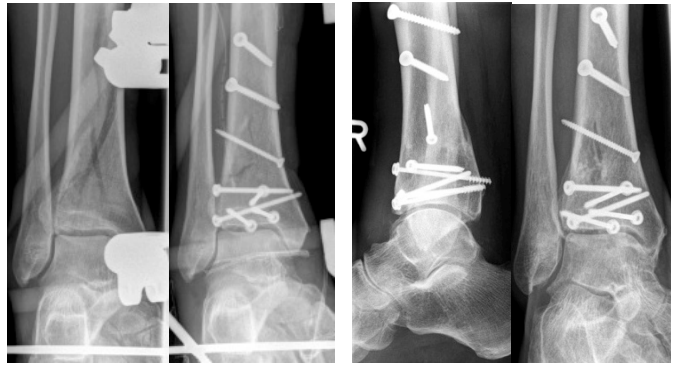

Fig. (5). Patient 5: Primary treatment with external fixation, secondary osteosynthesis with screws. Results after 36 months.

\section{DISCUSSION}

Reduction and retention with multiple $3.5 \mathrm{~mm}$ lag screws with interfragmentary compression allowed primary fracture healing in all cases without relevant callus formation.

Although lag screws develop high compression forces in the fracture zone that are sustained for the duration of fracture healing, they offer little resistance against other forces such as flexion and torsion.

The use of external fixation only permits movement within the fracture zone of several millimetres but ensures high rigidity in the plane of the Schanz-screw [1], which means that biomechanically the two techniques supplement each other in cases of low soft tissue involvement. Other studies with even larger patient collectives using an equivalent combination of osteosynthesis techniques and external fixation have shown similar encouraging results [7$11]$.

The lower degree of comfort of external fixation and longer immobilisation of the ankle had an effect on the range of movement in the ankle joint in another patient collective [10] though there was no significant association between the osteosynthesis technique and range of motion achieved in other studies.

In our cohort study there was no relevant restriction of range of motion in the ankle joint, particularly given the severity of primary joint damage.

Achieving good reconstruction of the pilon tibial joint surface appears to have a positive effect on treatment results. In comparison with other studies in which joint immobilisation lasted up to 12 weeks $[8,10,12,13]$, we were able to reduce immobilisation using joint-bridging orthotics and therefore early mobilisation of the ankle joint was possible. Immobilisation using hybrid- or Ilizarov-ringfixation not including the ankle appears to be technically impossible in those intra-articular comminuted fractures discussed here as, due to the close relation of the fracture to the joint, the stabilisation of bone fragments with small lag screws does not leave enough space for further implants. Furthermore, stabilisation within the tibial pilon would not allow stabilisation distally to the fracture, but only within the fracture area.

It is known that avoiding the use of a plate is advantageous for soft tissue protection [11], and multiple studies have shown that plating is associated with a higher rate of wound healing problems $[8,14-16]$ and in rare cases might even lead to amputation [17]. With the introduction of minimally invasive techniques of osteosynthesis there has been an overall reduction in soft tissue complications [7, 18], although some authors have reported infection rates of up to $17 \%$ postoperatively after plating [15]. Using interfragmentary screws combined with external fixation was associated with a significant reduction in soft tissue complications [8].

We achieved good wound healing without infection even though two out of five patients had to be treated with open wound treatment and artificial skin coverage for several days after sustaining compartment syndrome, despite the critical soft tissue situation.

No cases of delayed fracture healing or osteomyelitis were detected although a higher rate of delayed wound healing after using external fixation has been reported in the literature, possibly due to lack of bone continuity in defect fractures [19]. Addition of a lag screw does appear to positively influence bone healing rates [17]. In our patient collective fracture healing was without complications, and no relevant callus formation was detected, even in extensive fracture zones. Open reduction and fixation with AO small fragment screws allows optimal reconstruction especially of the joint surface, including specific stabilisation of smaller bone fragments while sparing the periosteum. A limitation of this study was the relatively low number of cases. On the other hand the follow-up period was relatively long.

Functional results using the AOFAS score were good in medium term despite severe primary damage to the joint surface. Long term results have been discussed controversially in the literature. On one hand the severity of secondary arthrotic deformities is known to correlate with the severity of primary damage of the joint surface [11]; on the other hand ankle joint function has been reported to improve over the years following initial trauma $[8,9]$.

\section{CONCLUSION}

Using lag screws in combination with external fixation due to a lack of sufficient space for a locking plate after reconstruction of the bony alignment serves us well as a proven technique in cases with extensive bone and soft tissue damage.

\section{ACKNOWLEDGEMENT}

Declared none.

\section{CONFLICT OF INTEREST}

The authors confirm that this article content has no conflicts of interest.

\section{REFERENCES}

[1] Rüedi TP, Murphy WM, Renner M, et al. AO Prinzipien des Frakturmanagements. Germany: Thieme Verlag 2003.

[2] Kellam J, Waddell J. Fractures of the distal tibial metaphysis with intra-articular extension-the distal tibial explosion fracture. J Trauma 1979; 19: 593-601.

[3] Oestern H, Tscherne H, Sturm J, et al. Classification of the severity of injury. Unfallchirurg 1985; 88: 465-72.

[4] Perlick L, Köck F, Anders S, et al. Das ärztliche Gutachten. Orthop Unfallchir 2011; 1037-57.

[5] Kitaoka HB. Salvage of nonunion following ankle arthrodesis for failed total ankle arthroplasty. Clin Orthop Relat Res 1991; 268: $37-43$.

[6] Kellgren J, Lawrence J. Radiological assessment of osteoarthrosis. Ann Rheum Dis 1957; 16: 494-502. 
[7] Leonard M, Magill P, Khayyat G. Minimally-invasive treatment of high velocity intra-articular fractures of the distal tibia. Int Orthop (SICOT) 2009; 33: 1149-53.

[8] Marsh J, Smith S, Do T. External fixation and limited internal fixation for complex fractures of the tibial plateau. J Bone Joint Surg Am 1995; 77: 661-73.

[9] Marsh JL, Weigel DP, Dirschl DR. Tibial plafond fractures. How do these ankles function over time? J Bone Joint Surg Am 2003; 85: 287-95.

[10] Okcu G, Aktuglu K. Intra-articular fractures of the tibial plafond: A comparison of the results using articulated and ring external fixators. J Bone Joint Surg Br 2004; 86: 868-75.

[11] Wyrsch B, Mcferran MA, Mcandrew M, et al. Operative treatment of fractures of the tibial plafond. A randomized, prospective study. J Bone Joint Surg Am 1996; 78: 1646-57.

[12] Endres T, Grass R, Biewener A, et al. Vorteile der minimalinvasiven Reposition, Retention und Ilizarov-(Hybrid) Fixation bei Pilon-tibiale-Frakturen unter besonderer Berücksichtigung von C2/C3-Frakturen. Unfallchirurg 2004; 107: 273-84.
[13] Saleh M, Shanahan M, Fern E. Intra-articular fractures of the distal tibia: surgical management by limited internal fixation and articulated distraction. Injury 1993; 24: 37-40.

[14] Dillin L, Slabaugh P. Delayed wound healing, infection, and nonunion following open reduction and internal fixation of tibial plafond fractures. J Trauma 1986; 26: 1116-9.

[15] Lau T, Leung F, Chan C, et al. Wound complication of minimally invasive plate osteosynthesis in distal tibia fractures. Int Orthop (SICOT) 2008; 32: 697-703.

[16] McFerran MA, Smith SW, Boulas HJ, et al. Complications encountered in the treatment of pilon fractures. J Orthop Trauma 1992; 6:195-200

[17] Pugh KJ, Wolinsky PR, Mcandrew MP, et al. Tibial pilon fractures: a comparison of treatment methods. J Trauma 1999; 47: 937-41.

[18] Pai V, Coulter G. Minimally invasive plate fixation of the tibia. Int Orthop 2007; 31: 491-6.

[19] Koulouvaris P, Stafylas K, Mitsionis G, et al. Long-term results of various therapy concepts in severe pilon fractures. Arch Orthop Trauma Surg 2007; 127: 313-20.

(C) Kiene et al.; Licensee Bentham Open.

This is an open access article licensed under the terms of the Creative Commons Attribution Non-Commercial License (http://creativecommons.org/licenses/by-nc/3.0/) which permits unrestricted, non-commercial use, distribution and reproduction in any medium, provided the work is properly cited. 